\title{
A OUVIDORIA DA UNB: HISTÓRICO, ACOLHIMENTO E ATUAÇÃO
}

\author{
Maria Ivoneide de Lima Brito ${ }^{1}$ \\ Larissa dos Santos Aguiar ${ }^{2}$
}

\begin{abstract}
Resumo
Este texto aborda os desafios e as limitações de uma Ouvidoria universitária pública federal, especificando o histórico de sua criação e refundação, seu acolhimento e os dados de sua atuação no contexto da Universidade de Brasília (UnB), destacando-a como importante canal de comunicação entre o cidadão e a Administração Pública, bem como a efetividade de seu contexto de atendimento.
\end{abstract}

Palavras-chave: Controle social. Educação superior. Ouvidoria. UnB.

\begin{abstract}
This text addresses the challenges and limitations of a Federal Public University Ombudsman, specifying the history of its creation and refoundation, its reception and the data of its performance in the context of the University of Brasilia (UnB), highlighting it as an important communication channel between the citizen and the Public Administration, as well as the effectiveness of its service context.
\end{abstract}

Keywords: Social control. Higher education. Ombudsman. UnB.

\section{DOI:10.37814/2594-5068.2020v3.p119-131}

1 Doutoranda do Programa de Pós-Graduação em Ciências e Tecnologias em Saúde da Faculdade de Ceilândia (UnB/FCE). Mestra em Educação pela Universidade de Brasília (2013). Especialista em Gestão Universitária pela UnB (2011) e em Linguística e Língua Portuguesa pela Faculdade da Terra de Brasília (2006). Graduada em Pedagogia, com ênfase em Orientação Educacional (2008), e em Letras pela Faculdade da Terra de Brasília (2003). Ouvidora da Universidade de Brasília. Professora voluntária no Curso de Terapia Ocupacional (FCE), bem como no Programa de Extensão Universidade do Envelhecer (UniSer) - (FCE). (www.ouvidoria.unb.br/) (ouvidoria@unb.br) 2 Mestranda em Educação Profissional pela Faculdade de Educação da Universidade de Brasília. Licenciada em Letras - Língua Portuguesa e Respectiva Literatura pela Universidade Católica de Brasília (2003). Possui Aperfeiçoamento em Redação e Revisão de Textos pela Universidade de Brasília (2007). Pós-Graduada em Língua Portuguesa pela Universidade Salgado Oliveira-RJ (2006) e Pós-Graduação lato sensu em Letras pela Universidade de Brasília (2008). Atua na área de revisão e padronização de textos acadêmicos e publicitários desde 2003. É servidora pública federal do Quadro de Pessoal da Fundação Universidade de Brasília desde 2012, atuando como Assessora Técnica da Ouvidoria da UnB, e Ouvidora da UnB substituta. (www.ouvidoria.unb.br/) (ouvidoria@unb.br) 


\section{INTRODUÇÃO}

A educação é um bem público, um direito social fundamental ao sujeito e que pode ser requerida pelo cidadão ao Estado, que, por sua vez, tem o dever de oferecê-la. Configura-se como garantia constitucional, prática social que, por meio de interação com o contexto nacional, apresenta-se como direito inalienável, condição essencial para a garantia dos direitos humanos, cabendo ao Estado sua oferta, manutenção e desenvolvimento. Nesse sentido, o País deve reverberar políticas públicas que propiciem o respeito à diferença e à diversidade, o exercício da cidadania plena e a democratização do acesso à educação, com vistas à universalização de todos os seus níveis, ao fim do analfabetismo e à promoção de uma educação superior de qualidade, entre outros olhares e caminhos que estão engendrados na questão.

Historicamente, o Brasil tem-se caracterizado como um país composto por unidades federativas demograficamente díspares, com frágeis políticas sociais e grande desigualdade de renda. Dados de 2010 ilustram essa proposição: 190.755 .799 milhões de habitantes, com 50\% em situação de pobreza e $65,2 \%$ dos trabalhadores brasileiros com mais de dez anos de carteira assinada recebendo até dois salários mínimos (IBGE, 2011). Não é muito diferente a realidade de 2016, cujo montante da população era superior a 207,7 milhões, com mais de 52,168 milhões de brasileiros vivendo abaixo da linha da pobreza. Esses parâmetros refletem a ausência de políticas sociais efetivas e assumem formas cada vez mais nefandas de exclusão social, que colocam o Brasil numa condição de país injusto, possuidor de terrível nódoa de desigualdade.

O panorama excludente tem efígies expressivas, sobremodo no campo da educação. Basta observar que até 2010 o País detinha 16 milhões de analfabetos absolutos, o que correspondia a 8,4\% da população total. O percentual de pessoas sem instrução ou com nível fundamental incompleto era de 50,2\%. Por sua vez, da população com mais de sete anos de idade, 11,2\% eram analfabetos; desses, aproximadamente 2,5 milhões estavam na faixa de escolaridade obrigatória - 6 a 14 anos (IBGE, 2011). Esses são dados atinentes à educação básica. Reflita-se, então, quanto ao levantamento efetivo dos aprendentes da educação superior ${ }^{3}$, área na qual se situa o objeto deste artigo e que, de forma integral, abarca o papel da educação.

Nessa direção, no transcurso do ano de 2019, momento em que são celebrados os 71 (setenta e um) anos da Declaração Universal dos Direitos Humanos, os 57 (cinquenta e sete) anos da Universidade de Brasília (UnB) e, ainda, os 8 (oito) anos da formalização da Ouvidoria da UnB, embora já em funcionamento desde 1993, segundo LYRA (2000), a Instituição é desafiada a: I) manter seu papel social de entidade educadora e de qualidade, mesmo em um contexto de neogerencialismo e patrimonialismo, do ponto de vista das políticas nacionais, com exacerbado corte de verbas para a educação superior; II) pensar a respeito do lema: como transformar a universidade em um espaço mais humano?; e, por conseguinte, III) responder ao anseio da comunidade acadêmica, no que tan-

3 Ao longo da história da educação brasileira, adotou-se a expressão "ensino superior". Contudo, a partir da promulgação da Lei de Diretrizes e Bases da Educação - Lei n 9.394, de 20 de dezembro de 1996 (BRASIL, 1996), houve alteração de nomenclatura para "educação superior". Outrossim, para contemplar tal dispositivo legal, no artigo, o termo "ensino superior" será utilizado quando o contexto histórico for anterior à publicação da referida Lei, e "educação superior" quando o debate sobre esse nível educacional estiver focado a partir de 1996. 
ge ao controle e à participação social, tendo como base a Ouvidoria e, seguindo a mesma linha de análise no que se refere a seu histórico, a seu acolhimento e a sua atuação; IV) como transformar a Ouvidoria da UnB em um espaço mais acolhedor e humano? Para tanto, é mister destacar algumas reflexões provenientes da área de Direitos Humanos, no próximo tópico.

\title{
2 A DECLARAÇÃO UNIVERSAL DOS DIREITOS HUMANOS E A EDUCAÇÃO SUPERIOR
}

O ano de 2019 é o marco da celebração dos 71 (setenta e um) anos da Declaração Universal dos Direitos Humanos (DUDH), inicialmente proclamada em 1948, mediante o alicerce de ações e políticas públicas que possam fomentar a composição de uma geração de cidadãos mundiais que acredita, trabalha e vela por uma sociedade mais justa, serena, igualitária; um mundo fundamentado no alicerce da paz, do respeito e do amor fraternal. Tendo esse referencial como espectro, o qual, por conseguinte, contribui para a edificação de uma geração de pessoas, cidadãos ativos, educadores, que administram e fazem gestão de seus conflitos, independentemente do seu tamanho, mediante os princípios democráticos, os direitos e as garantias individuais, e, sobremodo, valorizando a liberdade, tanto de ação quanto de escolha e de expressão, conforme proclamada pela sua Assembleia-Geral:

\begin{abstract}
A Assembleia-Geral proclama a presente Declaração Universal dos Direitos Humanos como o ideal comum a ser atingido por todos os povos e todas as nações, com o objetivo de que cada indivíduo e cada órgão da sociedade, tendo sempre em mente esta Declaração, se esforce, através do ensino e da educação, por promover o respeito a esses direitos e liberdades, e, pela adoção de medidas progressivas de caráter nacional e internacional, por assegurar o seu reconhecimento e a sua observância universal e efetiva, tanto entre os povos dos próprios estados-membros, quanto entre os povos dos territórios sob sua jurisdição. (DECLARAÇÃO UNIVERSAL DOS DIREITOS HUMANOS, p. 4)
\end{abstract}

É com esse olhar que a UnB, nesse período, é desafiada a ter cada vez mais consciência de seu papel social, ato que, certamente, abarca o seu saber-fazer e o seu saber-ser-pedagógico e suas funções sociais, sua totalidade, ou seja, o campo da educação superior. Nessa direção, é mister destacar que esfera em comento é delineada como uma área implexa de pesquisa que se destina, em grande parte na História mundial e, por conseguinte, no País, a formar elites, composta por conflitos estruturais e contrassensos, como a definição do papel que ela deve desenvolver na sociedade. Segundo SANTOS (1999 e 2004), na atual conjuntura global, as universidades vivem uma crise que envolve três dimensões: hegemônica, de legitimidade e institucional.

A primeira crise é resultado da contradição entre a função tradicional da Universidade e as novas atribuições que the foram conferidas, em particular, no transcurso do século XX. Destarte, de um lado encontra-se seu papel de fabricante de cultura e conhecimento particularizado e, do outro, a obrigatoriedade de formar força de trabalho qualificada para o mercado, o que corrobora uma visão pragmática do processo educativo.

Por sua vez, a segunda crise, a da legitimidade, para o autor, emerge em função "de a universi- 
dade ter deixado de ser uma instituição consensual em face da contradição entre a hierarquização dos saberes especializados, por meio das restrições do acesso e da credenciação das competências". Fator que eclode em uma universidade que deve ser produtora e que hierarquiza saberes de alto padrão, ponto que preconiza múltiplas exigências acadêmicas, ao passo que contribui para a democratização desse espaço e a socialização desse conhecimento com mais oportunidades para as classes populares, almejando sua promoção social, tendo em vista que o fator escolarização é considerado como caminho para ampliação de renda, a sua democratização social. Essa crise exalta duas tensões, a saber: a da contenção e a da expansão do acesso à educação superior, o que pode ser observado na inquietação do autor:

No momento em que a procura da universidade deixou de ser apenas a procura de excelência e passou a ser também a procura da democracia e de igualdade, os limites da congruência entre os princípios da universidade e os princípios da democracia e da igualdade tornaram-se mais visíveis: como compatibilizar a democratização do acesso com os critérios de seleção interna? Como fazer interiorizar numa instituição que é, ela própria, uma sociedade de classes os ideais de democracia e de igualdade? Como fornecer aos governados uma educação semelhante à que foi fornecida aos governantes sem provocar um excesso de democracia e, com isso, a sobrecarga do sistema político para além do que é tolerável? Como é possível, em vez disso, adaptar os padrões de educação às novas circunstâncias sem promover a mediocridade e descaracterizar a universidade? (SANTOS, 1999, p. 184)

Já a terceira crise, a institucional, é marcada pela contradição entre o anseio pela autonomia universitária e a pressão vigente para "submeter esta última a critérios de eficácia e de produtividade de natureza empresarial ou de responsabilidade social" a um Estado avaliador, que exalta suas funções de controle, fiscalização, regulação e intervenção, mediante seus órgãos de controle e suas respectivas legislações, que, não raro, não foram feitas e direcionadas às universidades, posto que parecem não respeitar suas nuances e peculiaridades, contemplando a educação como um produto, um insumo do mercado e do capital, bem como das políticas internacionais de mercantilização da educação pública (ato que, por via de regra, representa uma luta contínua entre o espaço social e de autonomia universitária e o controle regulatório e intervencionista do Estado).

Por conseguinte, as crises supracitadas acabam por fomentar todo o cenário brasileiro e contribuem para desenhar o papel da universidade moderna, um campo heterogêneo, marcado por elevada complexidade, por um conjunto de diversidades e que fomenta a necessidade de uma revisão sistemática de sua função, de sua missão e de seu plano institucional e, ainda, de sua forma de se

relacionar com a comunidade interna e com os anseios da sociedade em geral. É nesse âmbito de atuação, desafios e contradições que se situa a UnB.

\section{A UNB: CAMINHOS E DESCAMINHOS}

No limiar da Universidade de Brasília, nas palavras de DARCY RIBEIRO (1986), explicitou-se a sua função social no momento de sua fundação: criada para que ousasse, a fim de que, à vanguarda de seu tempo, enquanto universidade-semente, se estruturasse como a Universidade Nova, 
na Nova Capital, sendo um centro nacional de criatividade científica e cultural, que pensa o Brasil como problema e lhe propõe soluções. A UnB é um sublime projeto de autonomia e de liberdade para pensar, para pesquisar, para ensinar, para experienciar.

Até meados de 1960, para além do projeto original da Faculdade de Filosofia, Ciências e Letras da Universidade de São Paulo (1934) e a criação da Universidade do Distrito Federal (1935), no Rio de Janeiro, o Brasil não fora marcado por grandes premissas ou tradição em relação à educação superior, pontuando-se a baixa taxa de atendimento à população, o que ainda ocorre hoje. Dessa feita, no dia da inauguração de Brasília, objetivando mudar esse cenário e reestruturar a educação superior no País, o então presidente Juscelino Kubitschek de Oliveira encaminhou ao Congresso Nacional uma mensagem solicitando a criação da Universidade de Brasília, na nova capital do Brasil.

Com essa ordenança, a Universidade de Brasília emerge em 1961 e é pensada como uma proposta de oposição ao modelo arcaico, austero, elitista e sucateado até então vigente, nas universidades brasileiras. E, com esse olhar, responde ao grito do manifesto de 1932 e, por sua vez, preconiza a Reforma Universitária de 1968, como um revide eficiente para modernizar a educação superior no País, com responsabilidade elevada, a de consubstanciar o desenvolvimento do Brasil e suas nuances. Uma utopia bem arquitetada, um projeto desafiador, original; um centro de reflexão, um núcleo de criticidade e de busca de soluções para os problemas nacionais, uma universidade endereçada a espíritos inovadores, que coadunou com a fundação da nova capital federal e com os valores concernentes à ideologia nacional-desenvolvimentista em voga à época.

A UnB é uma utopia vetada, é uma ambição proibida, por agora, de exercer-se [...] é, sobretudo, o compromisso de esforçar-se, permanentemente, incansavelmente, para ser a universidade necessária [...] casa da cultura brasileira, se faça capaz de ajudar o Brasil a formular o projeto de si próprio: a nação de seu povo, ordenada e regida por sua vontade soberana, como o quadro dentro do qual ele há de conviver e trabalhar para si próprio. (RIBEIRO, 1978, p. 41)

Nessa direção, a Universidade de Brasília é formada como instituição pública de educação superior, fomentada sob a égide da Fundação Universidade de Brasília (FUB), Lei n 3.998, de 15 de dezembro de 1961. Manifesta-se como uma proposta moderna de formação acadêmica, apoiada na premissa de criar uma elite nacional, mediante a visão do capitalismo autossustentado.

Segundo seu Plano Diretor, publicado em maio de 1962 e reeditado no bojo de seu 50 aniversário, a UnB deveria ser capaz de constituir profissionais habilitados ao exercício de atividades técnicas requeridas para o desenvolvimento econômico nacional, o que se observa em alguns de seus objetivos originais:

I) formar cidadãos responsáveis, empenhados na procura de soluções democráticas para os problemas com que se defronta o povo brasileiro na luta pelo desenvolvimento; II) preparar especialistas altamente qualificados em todos os ramos do saber, capazes de promover o progresso social pela aplicação dos recursos da técnica da ciência; III) reunir e formar cientistas, pesquisadores e artistas e lhes assegurar os necessários meios materiais e as indispensáveis condições de autonomia e de liberdade para se devotarem à ampliação do conhecimento e à sua aplicação à serviço do homem. (FUB, $1962, \mathrm{~s} / \mathrm{n})$ 
Quanto às contradições que reverberam na fundação da UnB e seu papel social, pontuam-se as seguintes críticas:

\begin{abstract}
O plano da Universidade de Brasília representa, portanto, "um núcleo de controvérsias" que retrata as ambiguidades e as ilusões do projeto burguês lastreado no modelo nacional-desenvolvimentista que se inspira no nacional e se sustenta no internacional, preconizando a modernização conservadora. Nos objetivos dessa universidade está imbricada essa mesma contradição - ela privilegia o nacional, utilizando modelos e formas de outros países, recursos financeiros externos e, sobretudo, implementado a modernização "sem mudanças", ao mesmo tempo que se acredita crítica e comprometida com os problemas do povo. (FONSECA, 1997, p. 28)
\end{abstract}

Na prática, a UnB é uma universidade na vanguarda de seu tempo, com vistas a internalizar novas concepções e modelos para a educação superior no País e na América Latina. Seu projeto é utópico, arquitetado como um núcleo cultural, centro de excelência em ensino e extensão. Uma exímia instituição de pesquisa direcionada para todos os ramos do saber e de divulgação científica, tencionando formar profissionais necessários ao Brasil, almejando a progressão do Brasil e a resolução de seus pontos nevrálgicos. Entre as funções básicas de sua composição, destacam-se:

Facilitar aos poderes públicos o assessoramento de que carecem em todos os ramos do saber, o que somente uma universidade pode prover.

Dar à população de Brasília perspectiva cultural que a liberte do grave risco de fazer-se medíocre e provinciana, no cenário urbanístico e arquitetônico mais moderno do mundo. (RIBEIRO, 1961, p. 9)

A UnB foi constituída para ser uma universidade emancipatória, democrática, inovadora, hodierna, autônoma e criadora, de função social inigualável diante da educação superior, que reverbera a interdisciplinaridade e a integração das múltiplas áreas do conhecimento. Na prática, ela é um instrumento de superação de atraso nacional, de papel libertário e transformador.

No desenho original de seus Institutos Centrais, Faculdades e Órgãos Complementares, foi projetada para a execução de cursos básicos e introdutórios, cursos de bacharelados, cursos de formação científica e novas modalidades de programas de pós-graduação.

Inicialmente edificada com oito Institutos Centrais de Ensino e Pesquisa e cinco faculdades ${ }^{4}$, espaços nos quais os discentes passariam por um ciclo básico geral ou cursos troncos, para, só depois de dois anos, deliberarem por sua carreira e completarem seus estudos em Institutos e Faculdades. Outro conjunto de anexos compreendia: a Biblioteca Central, o Centro de Teledifusão Educativa, a Editora, o Museu, o Centro Militar, o Estádio Universitário, as Casas Nacionais de Língua e Cultura e o Centro Brasileiro de Estudos Portugueses, extraído do modelo norte-americano.

Seu organograma previa outros órgãos culturais, como o Centro Recreativo e Cultural, Estádio Universitário, Museu da Civilização Brasileira, Museu da Ciência, Casa Internacional, Centro de

4 De acordo com o Plano Orientador da Universidade, os Institutos Centrais são: IC de Matemática, IC de Física, IC de Química, IC de Biologia, IC de Geociência, IC de Ciências Humanas, IC de Letras e IC de Artes. As Faculdades: Arquitetura e Urbanismo, Engenharia, Educação, Direito-Economia-Administração-Diplomacia, Ciências Agrárias e Ciências Médicas. (FUB, 1962, s/n) 
Educação Elementar e Médica, Habitações para os servidores e discentes, Aula Magna, Centro Educacional com escolas primárias e média de demonstração para os alunos da Faculdade de Educação, Centro de Assistência Médica e Dentária, Casa Internacional, entre outras. Infelizmente, esse projeto, amplamente delineado e tencionado por Anísio Teixeira e Darcy Ribeiro, jamais foi concluído, o que é ratificado na fala de seu mentor:

De tudo isso que poderia ter sido, só se salvou o Minhocão. Mas, ao seu lado, quanta arquitetura pretensiosa, vitrineira e tola. Meditando ali, naquela tarde, frente ao que é hoje o campus da UnB, eu aprendi que uma universidade não é apenas um conjunto de edifícios na tarde do cerrado goiano. A UnB é uma utopia vetada, é uma ambição proibida, por agora, de exercer-se. Mas permanece sendo, esperando, como a nossa utopia concreta, pronta a retomar-se para se repensar e refazer, assim que recuperarmos a liberdade de definir o nosso projeto como povo e a universidade que deve servi-lo. (RIBEIRO, 1978, p. 41)

De acordo com SALMERON (2012), a UnB viveu três fases em sua história, espelhando o contexto brasileiro:

I) O ápice de sua criação, fundação e utopia (1961 a 1964).

II) O regime autoritário/militar, marcado pela repressão, o controle ideológico e a coerção (1964 a 1985) (período dos reitores interventores): o campus foi dominado e invadido por policiais militares e do exército por inúmeras vezes durante o ano de 1964. No dia 9 de abril do referido ano, data da promulgação do Ato Institucional n.1, a UnB foi sobrepujada por tropas bélicas, momento em que treze ensinantes foram demitidos, inclusive Anísio Teixeira, além da prisão de inúmeros discentes, ato que fomentou a imposição de uma política de silêncio e terror e a quebra de sua autonomia:

Dia 09 acontecera uma verdadeira operação bélica. A tropa motorizada, armada até de metralhadora, cercara o campus da UnB. Supunham que iriam encontrar um grupo de guerrilheiros. Não encontraram nada. Nem um canivete. Curioso foi o troféu que ergueram no dia seguinte: duas provas de subversão. Livros subversivos. Era a obra de Le Corbusier (grande arquiteto e mestre de Niemeyer), confundido com Rolando Corbisier intelectual do ISEB. Outra prova foi a bandeira da China comunista ocupando três colunas do Correio Braziliense do dia 10.04.64. Só que a bandeira era do Japão com a qual mantínhamos relações diplomáticas.

Nove companheiros foram presos e levados ao Teatro Nacional (então apenas um buraco oco servindo de aquartelamento da Polícia Militar) e, com o maior desrespeito, a título de realizar vistoria, despiram os professores. (MENEZES, 1989, p. 60)

Essas invasões desabrocharam em episódios como o Dia da Vergonha (1964), no qual diversos docentes foram aprisionados e levados a um pátio militar para serem desnudados e arrasados durante o turno vespertino, entre tantas outras ações e desmandos. Outra data marcante deu-se um ano depois, no Dia da Diáspora, em 18 de outubro de 1965. Depois da expulsão de 15 educadores acusados de subversão, 209 professores assinaram demissão coletiva, em protesto contra a repressão. Em um só momento histórico, a Instituição perdeu $79 \%$ de seu corpo docente, além da prisão de diversos discentes (RIBEIRO, 1978). 
Isto é o que me entrou pelos olhos naquela tarde, percorrendo o campus da UnB. Percebi ali, claramente, que a verdadeira Universidade de Brasília é a utopia concreta que subsiste calada entre seus muros no espírito dos estudantes e dos professores que guardam fidelidade ao seu espírito; mas é, também, a universidade enclausurada, que vive onde sobrevivem os que a conceberam; e é, sobretudo, a que ressurgirá em quantos, amanhã, hão de reencarná-la em liberdade e dignidade. (RIBEIRO, 1978, p. 46)

III) Da redemocratização aos dias atuais. A década de 1980 foi marcada pelo processo de redemocratização da Universidade. Na sequência, veio a ampliação dos campi, por meio do Programa de Apoio a Planos de Reestruturação e Expansão das Universidades Federais (Reuni), Decreto n 6.096/2007, eclodindo na ampliação de vagas nos cursos de graduação da Universidade, no transcurso de 2008 a 2012, nos períodos diurno e noturno, cujos dados confirmam que a UnB passou de 4.830 vagas em 2008 para 8.488 vagas em 2012, além do acréscimo de 37 novos cursos.

Um marco de sua história deu-se no transcurso de 2016, quando a primeira mulher foi eleita Reitora da UnB, professora Márcia Abrahão Moura, uma baliza ímpar na vida da Universidade, que, entre seus atos de gestão, contribuiu para fomentar o papel da Ouvidoria da UnB e a consolidação dos direitos dos cidadãos, mediante o Ato da Reitoria $n^{\circ} 1114 / 2017$, que constituiu 0 Conselho de Direitos Humanos da UnB (CDHUnB), enquanto mecanismo de defesa e promoção da solidariedade humana.

Na sequência, em âmbito nacional, por intermédio do Decreto $n^{\circ} 9.400$, de 4 de junho de 2018, o Presidente da República institui o Fórum Nacional de Ouvidores dos Direitos Humanos, no âmbito do Ministério dos Direitos Humanos.

\section{A OUVIDORIA DA UNB: HISTÓRICO, ACOLHIMENTO E ATUAÇÃO}

\subsection{Marco legal, criação, silêncio e recriação}

A Ouvidoria universitária apresenta-se como importante ferramenta para conciliar o cidadão (suas demandas) e o espaço universitário, exaltando, dessa feita, o espaço da democracia, do controle e da participação social. Instituir uma Ouvidoria na UnB, outrossim, é permitir que o processo de aperfeiçoamento educacional possa atuar de forma contínua e progressista.

É com esse olhar que a UnB executa o que determina o art. 37 da Constituição da República Federativa do Brasil de 1988, no que tange aos princípios constitucionais da publicidade e da eficiência, entre outros, ao exaltar o papel da Ouvidoria, cuja base legal é marcada por normativos internos que regulamentam o seu trabalho: 1) a Resolução do Conselho Universitário $n^{\circ} 7 / 2011$, que reverbera emenda ao Estatuto e alterações no Regimento Geral da UnB, autorizando a criação da Ouvidoria na estrutura organizacional, bem como a Resolução nº 0012/2018, de 20 de março de 2018, e seus anexos, que aprova o novo Regimento Interno; 2) a Instrução Normativa da Reitoria $n^{\circ} 1 / 2011$, além das Instruções da Reitoria $n^{\circ} 0001 / 2018$ e n 0002/2018, que normatizam, entre outros pontos, os prazos máximos a serem seguidos pelas áreas administrativas e acadêmicas da 
Instituição para atendimento às manifestações encaminhadas, bem como delineiam procedimentos que subsidiarão as atividades desenvolvidas.

A Ouvidoria da UnB observa, ainda, o teor da Instrução Normativa $n^{0}$ 5/2018, da Ouvidoria-Geral da União, que integra a Controladoria-Geral da União, que revogou a Instrução Normativa $n^{0}$ 1/2014 da Ouvidoria-Geral da União, a qual ressalta a premissa de: 1) adjudicar eficácia ao disposto no art. $37, \S 3^{\circ}$, da Constituição Federal de 1988 , que assevera aos cidadãos o direito de compartilhar da gestão da Administração Pública e consubstancia a atuação das unidades de Ouvidoria; 2) fomentar, nas atividades de avaliação, monitoramento e controle da Administração Pública, a execução da legitimidade, consoante preceitua o art. 70 da Constituição Federal; 3) engendrar o desempenho sistêmico e interligado das Ouvidorias do Poder Executivo Federal, com a premissa de melhorar a prestação de serviços públicos e o acolhimento aos cidadãos. E explana, ainda, o Decreto n 9.492/2018, o qual estrutura e entrelaça os mecanismos e as instâncias democráticas de escutatória e a ação conjunta entre a Administração Pública Federal e a sociedade civil, no que tange à participação, amparo e defesa dos direitos dos usuários. E, em conjunto, a Instrução Normativa Conjunta CRG/OGU n $7 / 2018$, que preconiza normas de recepção e tratamento de denúncias e outras comunicações de irregularidade e as ordenanças para a salvaguarda de identidade do manifestante.

Não obstante, a Ouvidoria também se fundamenta na Lei $n^{\circ} 13.460 / 2017$, a qual destaca pontos oportunos acerca da participação, proteção e defesa dos direitos do usuário dos serviços públicos da Administração Pública, além de fomentar o papel das Ouvidorias no âmbito do Poder Executivo Federal. Por conseguinte, segue amplamente o Decreto $n^{\circ}$ 9.094/2017, que traz como ideia subjacente a simplificação do atendimento prestado aos usuários dos serviços públicos, entre outros normativos da área.

Convém salientar que as Ouvidorias universitárias brasileiras têm quase trinta anos de existência e fazem parte do processo de redemocratização do País, o qual se deu com a queda do Regime Militar, no final da década de 1970 (FNOU, 2017, p. 49). A Ouvidoria da UnB, por sua vez, foi criada em 1993, conforme LYRA (2000), sendo a segunda Ouvidoria universitária em âmbito nacional (a primeira foi a da Universidade Federal do Espírito Santo, em 1992). Importante aqui mencionar uma curiosidade: a Ouvidoria da UnB, criada em 1993, foi desativada em 1997 por motivos não definidos de modo claro. Há muito que se refletir a partir desse "silêncio temporal". Fato que aqui é nomeado como a Ouvidoria interrompida. Nessa direção, a inquietação que fica é: quais motivos levaram os gestores dessa Instituição a adotarem esse possível retrocesso democrático?

A área supracitada volta a ser novamente ativada e instituída por meio de Regimento Interno aprovado pelo Conselho Universitário - órgão superior máximo de deliberação coletiva da Universidade -, mediante Resolução Consuni n 7/2011. Dessa feita, a formalização da Ouvidoria da UnB ocorre no transcurso de 24/5/2011, na administração do professor José Geraldo de Sousa Junior, mediante a premissa de democratização do espaço universitário e a convicção de que a Ouvidoria é, na visão do ex-Reitor, a "Pedagogia da Administração", um espaço marcado pela escutatória, a alteridade, o acolhimento e a afetividade. 


\subsection{O papel da Ouvidoria da UnB}

A Ouvidoria da UnB, entre outros aspectos de atuação, fundamenta-se na premissa de ser representante legítima do(a) cidadão(ã) que a procura, mediante o princípio da transparência, da imparcialidade, da confiabilidade, do comprometimento, da responsabilidade, da economicidade, da eficiência, da efetividade, da ética, da autonomia e da independência ao desempenhar os seguintes papéis sociais na qualidade de importante órgão de interlocução entre a sociedade/comunidade:

I) promover a participação do usuário na Administração Pública, em cooperação com outras entidades de defesa do usuário;

II) acompanhar a prestação dos serviços, visando garantir a sua efetividade;

III) organizar os mecanismos e canais de acesso dos interessados para encaminhar suas manifestações;

IV) orientar os docentes, os servidores técnico-administrativos, os alunos e a comunidade externa a respeito da melhor forma de encaminharem as suas demandas, instruí-las e acompanharem sua tramitação;

V) receber denúncias, reclamações, solicitações e sugestões acerca dos procedimentos e das práticas inadequadas ou irregulares, atuando no sentido de corrigi-los e aperfeiçoá-los com os órgãos competentes, buscando sempre o diálogo entre as partes;

$\mathrm{VI})$ recepcionar e encaminhar elogios relativos às políticas e aos serviços públicos prestados, sugerindo à chefia imediata o registro da menção elogiosa na pasta funcional do servidor junto ao Decanato de Gestão de Pessoas (DGP);

VII) encaminhar as manifestações acolhidas ao órgão competente, solicitando a devida apuração e retorno à Ouvidoria a fim de informar ao manifestante a respeito das providências tomadas;

VIII) propor a adoção de medidas para a defesa dos direitos do usuário, com vistas à correção e à prevenção de falhas e omissões dos responsáveis pela inadequada prestação do serviço público, bem como o aperfeiçoamento dos serviços;

IX) implantar ações e mecanismos que incentivem o exercício da cidadania e possibilitem ao administrador público a capacidade de análise e alteração de procedimentos;

X) promover a adoção de mediação e conciliação entre o usuário e a área/unidade acadêmica ou administrativa da UnB, ou entre as partes envolvidas no processo;

$\mathrm{XI}$ ) orientar a atuação das demais unidades de Ouvidoria da UnB (caso existam), promovendo sua coordenação em constituição de rede interna de atendimento às comunidades universitária e externa.

Na prática, a Ouvidoria da UnB funciona como espelho no sentido de que os gargalos identificados na Instituição sejam minimizados, os prazos sejam cumpridos, os processos sejam melhorados, as pessoas que trabalham com o público sejam amplamente capacitadas com vistas à prestação de serviços de excelência para o(a) cidadão(ã), e, por conseguinte, atua com os gestores, mostrando-Ihes um espaço de progresso e de correção de possíveis irregularidades, explicitando as deficiências como oportunidades.

\subsection{Acolhimento e atuação: dados de 2018}

A equipe da Ouvidoria da UnB trabalha com um olhar de diálogo como instrumento imprescindível para o convívio em sociedade e para a construção de uma rede de parcerias com as mais diver- 
sas áreas, ou seja, um trabalho embasado na alteridade, no acolhimento sensível e na afetividade, objetivando fortalecer a tríade de sua atuação:

I) ênfase no papel de acolhimento, almejando atuar como ponte entre a sociedade e o Estado, mediante ausculta humanizada e eficiente;

II) na condição de agente formador: capacitando sua equipe e a comunidade envolvida, mediante participação/execução de ações contínuas em relação à desmistificação e desmitificação desse espaço social e seus processos, compreendendo que o Ouvidor é, sobremodo, um ouvidor-educador, mediante a conscientização da construção de novos saberes;

III) articulação e fomento de ações que promovam a interação da Ouvidoria com as demais instâncias de participação social e a própria UnB, permitindo a promoção do intercâmbio entre Ouvidorias para a formação de servidores, viabilizando a cooperação técnica entre esses espaços de democracia e com outros institutos de promoção de direitos, sobremodo, os humanos.

Nessa direção, passos importantes foram executados no transcurso de 2018, como a adesão (2017) e a consolidação da implementação do e-Ouv, a participação nos mais diversos Conselhos da Universidade, em particular no Conselho de Direitos Humanos da UnB, em diversos seminários e grupos de trabalho da Instituição, entre outras ações que eclodiram nos seguintes dados, extraídos no interregno de 2011 a 2018 :

\section{GRÁFICO - Evolução anual de manifestações}

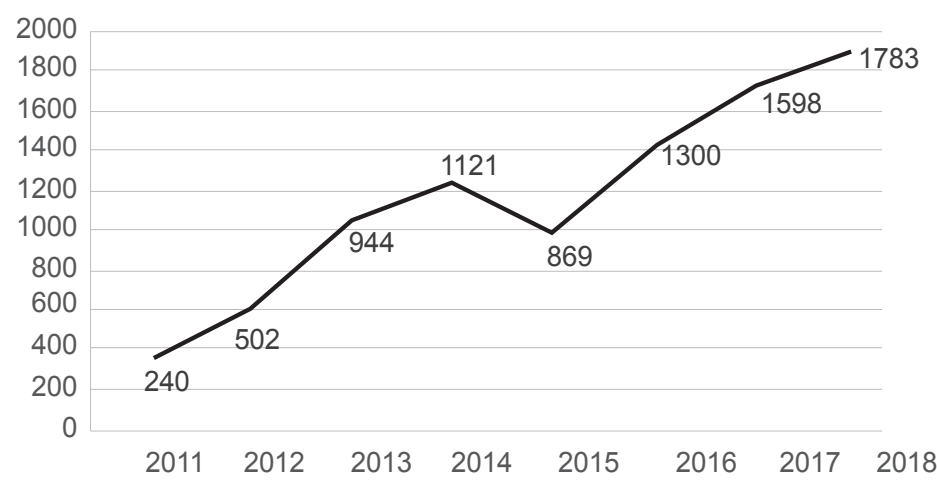
manifestações

Fonte: OUV/UnB, 2019

A Ouvidoria da UnB foi fundada em 24/05/2011, embora em funcionamento desde 1993. Naquele ano foram recepcionadas 240 manifestações. Em 2012, registrou-se o total de 502 manifestações, acopladas de 944 em 2013. No ano de 2014 foram 1.121 manifestações. Na sequência, o ano de 2015 consolidou o montante de 869 registros, sendo esse arrefecimento devido à desvinculação do Centro de Seleção e de Promoção de Eventos (Cespe) na UnB e sua mudança para a condição de Organização Social - Centro Brasileiro de Pesquisa em Avaliação e Seleção e de Promoção de 
Eventos (Cebraspe). Já o ano de 2016 consagrou o quantitativo de 1.300 casos, o de 2017, 1.598 e, por fim, o de 2018 revelou o total de 1.783 .

Um simples comparativo entre os dados provenientes do ano de fundação da Ouvidoria (2011) e os delineados em 2018 exibem um acréscimo considerável da ordem de 1.543 manifestações, ou seja, um significativo acréscimo de $742,5 \%$ (setecentos e quarenta e dois vírgula cinco por cento) desde a sua estruturação. Registre-se, ainda, importante expansão na complexidade dos casos, entre os quais: ideação suicida, denúncias em relação à postura inadequada de servidores, casos de assédio nos mais diversos âmbitos, questões atreladas à esfera da saúde mental.

No que tange ao quantitativo total, por tipo de manifestação recepcionada pela Ouvidoria, durante o ano de 2018, pontua-se que a solicitação/pedido de informação foi o ícone mais demandado, alcançando o percentual de $37 \%$ (trinta e sete por cento); seguido das reclamações, com $35,56 \%$ (trinta e cinco vírgula cinquenta e seis por cento); das denúncias com 12,35\% (doze vírgula trinta e cinco por cento); dos elogios com 7,13\% (sete vírgula treze por cento), da comunicação de irregularidade com $6,50 \%$ (seis vírgula cinquenta por cento) e, por fim, das sugestões, cujo montante foi de 1,46\% (um vírgula quarenta e seis por cento). Registre-se, por fim, que o índice de resolutividade das manifestações, para o período em voga, foi de 99,60\% (noventa e nove vírgula sessenta por cento).

Salienta-se, ainda, a crescente ampliação no grau de complexidade dos casos, entre os quais quatro assuntos são notórios - assédio; discriminação de gênero/raça e/ou homofobia; postura inadequada de servidor docente, técnico ou discente; violação de direitos individuais/coletivos e que, enquanto pontos subjacentes, trazem à tona questões "silenciadas", mas de profunda relevância, a saber: assuntos atinentes à saúde mental, à ideação suicida, entre outros.

Outro ponto a ser citado é que a Ouvidoria da UnB, a partir da adesão ao e-OUV, efetua pesquisa de satisfação entre seus usuários, mediante a premissa de ofertar serviços de qualidade e visualizar suas fragilidades, para efetuar correção de rumos e ações, a partir do monitoramento dos indicadores. Dessa feita, a partir do ano de 2018, o procedimento começou a ser implementado, a partir do sistema em esteira, com o uso do módulo que efetua esse levantamento, com a participação do cidadão. Pontua-se, todavia, que a contribuição é uma escolha de foro íntimo, de livre adesão. Em 2018, somente 120 usuários responderam à pesquisa. De todo modo, os dados funcionam como mecanismos para a melhoria de nossos serviços ao usuário, é a escutatória do cidadão.

\section{CONCLUSÃO}

O papel das Ouvidorias universitárias é de extrema importância para o cidadão, no que tange a sua área de atuação e seus pressupostos básicos: transparência, ética, respeito, controle e participação social, entre outros relevantes aspectos.

Dessa forma, a atuação da Ouvidoria da UnB objetiva a simplificação de processos e procedimentos anteriormente burocráticos e talvez até inacessíveis ao cidadão. São essas ações que, no contexto universitário, apresentam-se como excelentes instrumentos de governança e de accountability, os quais podem transformar inputs em indicadores, mediante atuação articulada e em rede. 
Nessa direção, assim como a UnB é precursora em seu tempo, a Ouvidoria deseja sê-lo, posicionando-se como referência nacional, ao compreender seu status quo e definir-se como a "Pedagogia da Administração", que, no bojo de sua atuação, pode contribuir para uma práxis de resultados, eficiente e eficaz, e, ainda, para a desconstrução das Ouvidorias simbólicas, ao fomentar, por conseguinte, os espaços democráticos, a inovação no contexto das universidades e, sobremodo, o papel do ouvidor-educador.

\section{REFERÊNCIAS}

DECLARAÇÃO UNIVERSAL DOS DIREITOS HUMANOS. UNIC/Rio. Janeiro 2009 (DPI/876). Disponível em: http:// www.onu.org.br/img/2014/09/DUDH.pdf. Acesso em: 28 jun. 2018.

FONSECA, Dirce Mendes da. A ideia da Universidade de Brasília: uma análise do discurso. 1997. Dissertação (Mestrado em Educação) - Faculdade de Educação, Universidade de Brasília, Brasília. Mimeografado.

FUNDAÇÃO UNIVERSIDADE DE BRASÍLIA (FUB). Plano orientador da Universidade de Brasília. Brasília: Universidade de Brasília, 1962.

Plano de expansão da Universidade de Brasília: Campus UnB-Planaltina: Campus UnB-Ceilândia/Taguatinga: Campus UnB-Gama. Brasília: FUB, 2005.

. Plano de reestruturação e expansão da Universidade de Brasília. Brasília: FUB, 2007.

. Plano de reestruturação e expansão da Universidade de Brasília. Brasília: FUB, 2008.

INSTITUTO BRASILEIRO DE GEOGRAFIA E ESTATÍSTICA - IBGE. Pesquisa nacional por amostra de domicílio 2010. São Paulo: IBGE, 2011.

INSTITUTO NACIONAL DE ESTUDOS E PESQUISAS EDUCACIONAIS - INEP. Censo da Educação Superior: resumo técnico. Brasília: Inep, 2005.

. Censo da educação superior: resumo técnico 2008. Brasília: Inep, 2009.

Censo da educação superior: resumo técnico 2010. Brasília: Inep, 2013.

LYRA, Rubens Pinto. O ouvidor universitário. 2000. Disponível em: <http://fnou.com.br/site/assets/publicacoes/ouvidor_universitario.pdf>. Acesso em: 25 maio 2018.

RIBEIRO, Darcy. Universidade de Brasília. Rio de Janeiro: CentBrasPesqEduc, 1961.

UnB: invenção e descaminho. Rio de Janeiro: Avenir Editora Limitada, 1978.

Universidade para quê? Brasília: Universidade de Brasília, 1986.

SALMERON, Roberto A. A universidade interrompida. Brasília: Universidade de Brasília, 2012.

SANTOS, Boaventura Sousa. Pela mão de Alice. O social e o político na pós-modernidade. 7. ed. São Paulo: Cortez, 1999. Cortez, 2004

A universidade do século XXI: para uma reforma democrática e emancipatória da universidade. São Paulo:

UNIVERSIDADE DE BRASÍLIA. I/ Relatório Semestral de 2017 da Ouvidoria. 2017. Disponível em: http://ouvidoria.unb. br/images/relatorios/Relatrio-2-2017.pdf. Acesso em: 28 jun. 2018. 